\title{
Effects of intravenous hydration on risk of contrast induced nephropathy and in- hospital mortality in STEMI patients undergoing primary percutaneous coronary intervention: a systematic review and meta- analysis of randomized controlled trials
}

Yong Liu ${ }^{1,2,3+}$, Daqing Hong ${ }^{4+}$, Amanda Ying Wang ${ }^{3{ }^{*}+}$, Rui Guo ${ }^{5+}$, Brendan Smyth ${ }^{3+}$, Jin Liu ${ }^{1,2}$, Guoli Sun ${ }^{1,2}$, Shiqun Chen ${ }^{1,2}$, Ning Tan ${ }^{1,2}$, Meg Jardine ${ }^{3}$, David Brieger ${ }^{3}$, Ahmed Shaman ${ }^{3,6}$, Shariful Islam ${ }^{3}$, Jiyan Chen ${ }^{1,2^{*}}$ (D) and Martin Gallagher $3,7^{*}$

\begin{abstract}
Background: The role of intravenous hydration at the time of primary percutaneous intervention (PCI) for STsegment elevation myocardial infarction (STEMI) remains unclear. Guidelines are vague, supported by low level evidence, and hydration is used less often than other clinical settings.To perform a systematic review and metaanalysis of all randomized controlled trials assessing intravenous hydration compared with non-hydration for prevention of contrast induced nephropathy $(\mathrm{CIN})$ and In-hospital mortality in patients with STEMI undergoing primary $\mathrm{PCl}$.
\end{abstract}

Methods: Medline, EMBASE and the Cochrane Register were searched to September 2018. Included studies reported the incidence of CIN, In-hospital mortality, requirement for dialysis and heart failure. Relative risks with 95\% confidence intervals (Cls) for individual trials were pooled using a random effects model.

Results: Three moderate quality trials were identified including 1074 patients. Overall, compared with no hydration, intravenous hydration significantly reduced the incidence of CIN by $42 \%$ (RR $0.58 ; 95 \% \mathrm{Cl}: 0.45$ to $0.74, p<0.001$ ). The estimated effects upon all-cause mortality (RR 0.56; $95 \%$ Cl: 0.30 to 1.02, $p=0.057$ ) and the requirement for dialysis (RR $0.52,95 \% \mathrm{Cl} 0.14-1.88, p=0.462$ ) were not statistically significant. The outcome of heart failure was not consistently reported.

\footnotetext{
* Correspondence: awang@georgeinstitute.org.au; chenjiyandr@126.com;

mgallagher@georgeinstitute.org.au; awang@georgeinstitute.org.au

'Yong Liu, Daqing Hong, Ying Wang, Rui Guo and Brendan Smyth

contributed equally to this work.

${ }^{3}$ The George Institute for Global Health, the University of Sydney,

Camperdown, Australia

${ }^{1}$ Department of Cardiology, Guangdong provincial Key Laboratory of

Coronary Heart Disease Prevention, Guangdong Cardiovascular Institute,

Guangdong General Hospital, Guangdong Academy of Medical Sciences,

School of Medicine, South China University of Technology Guangzhou,

Guangzhou, Guangdong, China

Full list of author information is available at the end of the article
}

(c) The Author(s). 2019 Open Access This article is distributed under the terms of the Creative Commons Attribution 4.0 International License (http://creativecommons.org/licenses/by/4.0/), which permits unrestricted use, distribution, and reproduction in any medium, provided you give appropriate credit to the original author(s) and the source, provide a link to the Creative Commons license, and indicate if changes were made. The Creative Commons Public Domain Dedication waiver (http://creativecommons.org/publicdomain/zero/1.0/) applies to the data made available in this article, unless otherwise stated. 
(Continued from previous page)

Conclusions: Intravenous hydration likely reduces the incidence of CIN in patients with STEMI undergoing primary PCl. However, for key clinical outcomes such as mortality, heart failure and dialysis the effect estimates were imprecise. Further high quality studies are needed to clarify the appropriate volume of fluid and effects on outcomes.

Keywords: Intravenous hydration, Contrast-induced nephropathy, ST-segment elevation-myocardial infarction, Primary percutaneous coronary intervention, acute kidney injury, dialysis, mortality

\section{Background}

Patients undergoing percutaneous coronary interventions (PCI) have a higher risk for the development of contrast induced nephropathy (CIN) [1]. CIN is associated with poorer outcomes for patients, including prolongation of hospital stay and higher mortality [2]. The risk in patients with ST-segment elevation-myocardial infarction (STEMI) undergoing primary PCI is even greater [3], and there are no treatments proven to mitigate this risk.

One recent study using intravenous hydration with normal saline before radiocontrast exposure, the cornerstone of CIN prevention across clinical medicine, showed a renal benefit for patients with STEMI [4]. But such therapy is less commonly used in patients undergoing primary PCI compared to elective PCI [5], probably due to the urgency of the procedure and concern about the development of congestive heart failure [6]. Clinical guidelines for PCI management recommend 'adequate preparatory hydration' [7], supported by lower level evidence, and more recent STEMI guidelines do not contain graded recommendations regarding the use of prophylactic hydration [8].

We performed a systematic review and meta-analysis of randomized controlled trials (RCT) in patients with STEMI undergoing primary PCI to examine the effect of prophylactic intravenous hydration compared to controls not receiving such hydration. The outcomes of CIN, requirement for dialysis, and In-hospital mortality were assessed.

\section{Methods}

The research question, search strategy, inclusion criteria, and statistical analyses were pre-specified. All RCT assessing intravenous isotonic fluid hydration compared with non-hydration for prevention of CIN in STEMI patients undergoing primary PCI were included. No language or publication status restrictions were imposed. Participants of any age undergoing primary PCI were considered, as were studies utilising pre- or post-hydration strategies. Studies involving the co-administration of potential nephroprotective agents (eg. N-acetylcysteine) were excluded. The primary meta-analysis outcome was incidence of CIN, defined as an absolute increase in serum creatinine of $\geq 0.5 \mathrm{mg} / \mathrm{dl}$
$(44 \mathrm{mmol} / \mathrm{l})$ or a relative increase of $\geq 25 \%$ from the baseline value after administration of contrast media during primary PCI $[4,5,9]$. The secondary outcomes included all-cause In-hospital mortality (as reported by the studies) and CIN requiring dialysis. Heart failure or acute pulmonary edema events were also recorded using study author definitions.

\section{Search strategy and data collection}

We searched MEDLINE, EMBASE, and Cochrane Central databases from the date of inception until September 2018. Tangential electronic exploration of related articles based on reference lists was also performed. Extensive hand searches of bibliographies of relevant reviews and related journals were also performed. Search terms included variants of hydration, fluid, nephropathy, contrast nephropathy, contrast-induced nephropathy, contrast media, contrast agent, kidney, renal, and myocardial infarction using text words and MeSH terms (see Additional file 1). Eligibility assessment of title and abstract and subsequent data extraction were performed independently by two authors ( $\mathrm{YH}$ and $\mathrm{DH}$ ) in an unblinded standardized manner using a study eligibility and data extraction form based on the Cochrane consumers and communication review group's template. Conference abstracts and letters retrieved from electronic databases were also included in screening process. Any discrepancy was resolved by the third person (RG).

The quality of the studies was assessed according to Cochrane Handbook for Systematic Reviews of Interventions and GRADE.

\section{Statistical analysis}

To assess study quality, we followed the guidelines in the Cochrane Handbook for Systematic Reviews of Interventions [10]. The primary outcome measure was quantified by computing the pooled risk ratio (RR) with 95\% confidence interval (CI) using a random-effects model. Trial sequential analysis (TSA) was used to estimate the number of additional patients and events that would be required to demonstrate an effect of the intervention where non-significant effects currently exist. These values and cumulative $\mathrm{Z}$ curve were calculated, applying the O'Brien-Fleming monitoring boundaries, by Trial Sequential Analysis 0.9 Beta (Copenhagen Trial 
Unit, Copenhagen, Denmark) software [11]. To explore variability in study results we performed subgroup analysis comparing studies using isotonic saline versus those using sodium bicarbonate solutions. Heterogeneity was assessed using $\mathrm{I}^{2}$ statistic (with 95\% CI) [12] where $\mathrm{I}^{2}$ values of 25,50 , and $75 \%$ may be considered as low, moderate, and high heterogeneity, respectively. The possibility of publication bias was assessed by a funnel plot and Egger's regression asymmetry test [13]. Statistical analysis was performed using STATA software (version 13.0).

\section{Results}

\section{Study selection}

The search yielded a total of 143 citations of which 99 were selected for full-text review. A flow diagram of study selection is presented in Fig. 1.

\section{Study characteristics}

Three RCTs were selected for the review and meta-analysis all of which reported the incidence of CIN as defined above. All three studies were single centre studies that enrolled adult patients with STEMI undergoing primary PCI. A total of 1085 patients were randomized, of whom 1074 were included in the primary analysis. Individual study characteristics, patient populations and key outcomes are presented in Table 1 and Additional file 2: Table S1.
Risk of bias and quality of clinical trials

The individual studies were judged to be of moderate quality with the risk of bias is summarised in Fig. 2 and Additional file 3: Figure S1. In addition to the absence of allocation concealment and blinding, other potential indicators of moderate study quality were that no study reported the volume of intravenous fluid received by the control group and that reporting of treatment variation (eg. reduction in infusion rate or cessation of hydration) in response to the development of pulmonary edema or hypotension was inconsistent. GRADE tool also suggested high quality for quality of evidence at CIN and in-hospital mortality (Additional file 4: Figure S2).

\section{Incidence of CIN}

The incidence of CIN was reported in 1074 patients who had completed the studies and were included in the final analysis. Isotonic fluid hydration was given to $612 \mathrm{pa}-$ tients and 462 patients were in control group. The overall incidence of CIN in patients receiving intravenous isotonic fluid hydration was $15.7 \%$ (96/612) compared with $26.4 \%(122 / 462)$ in the control group. Compared with no hydration, intravenous hydration significantly reduced the incidence of CI-AKI by $42 \%$ (RR 0.58 ; $95 \%$ CI: 0.46 to $0.74, p<0.001)$ using a random effects model (Fig. 3a), so did that with fixed effect model (Additional file 5: Figure S3). There was no significant heterogeneity among the studies $\left(\mathrm{I}^{2}=0.0 \%\right.$, chi-square $=$ $0.50, \mathrm{df}=2, p=0.7771)$. The effect of intravenous fluid

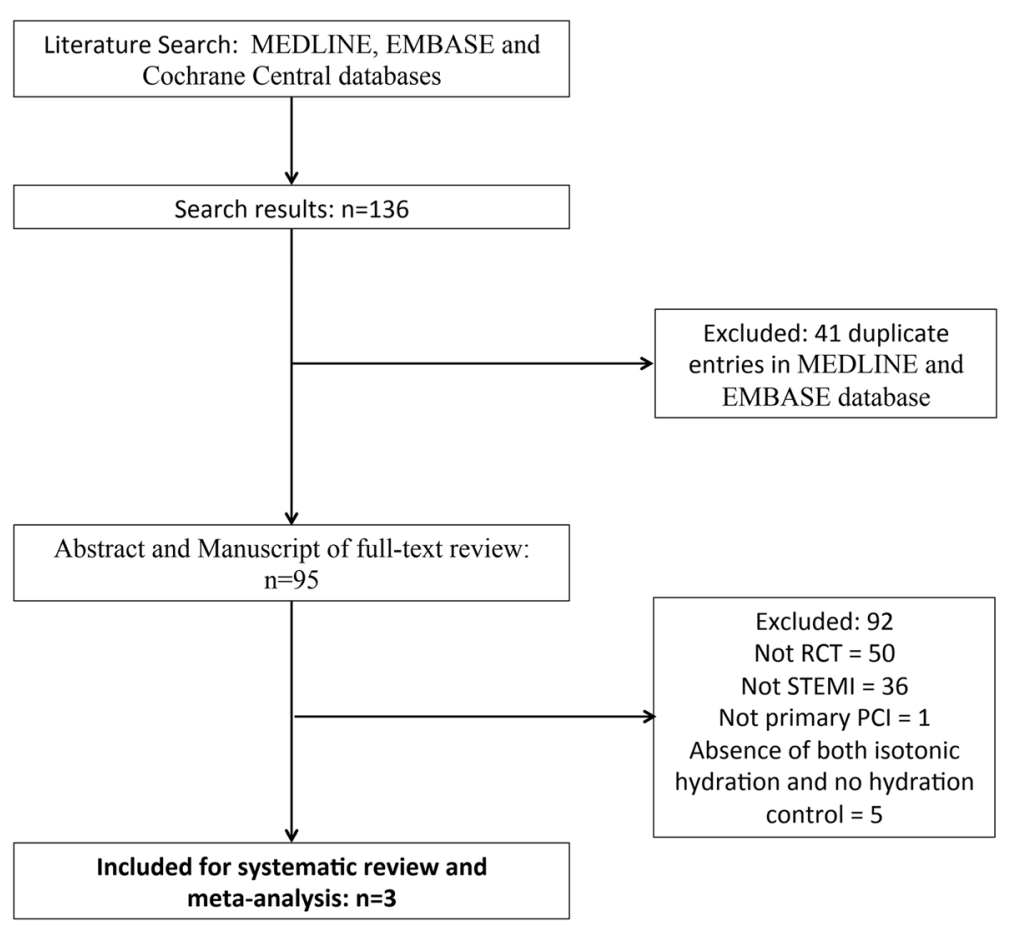

Fig. 1 Study flow diagram of study selection 


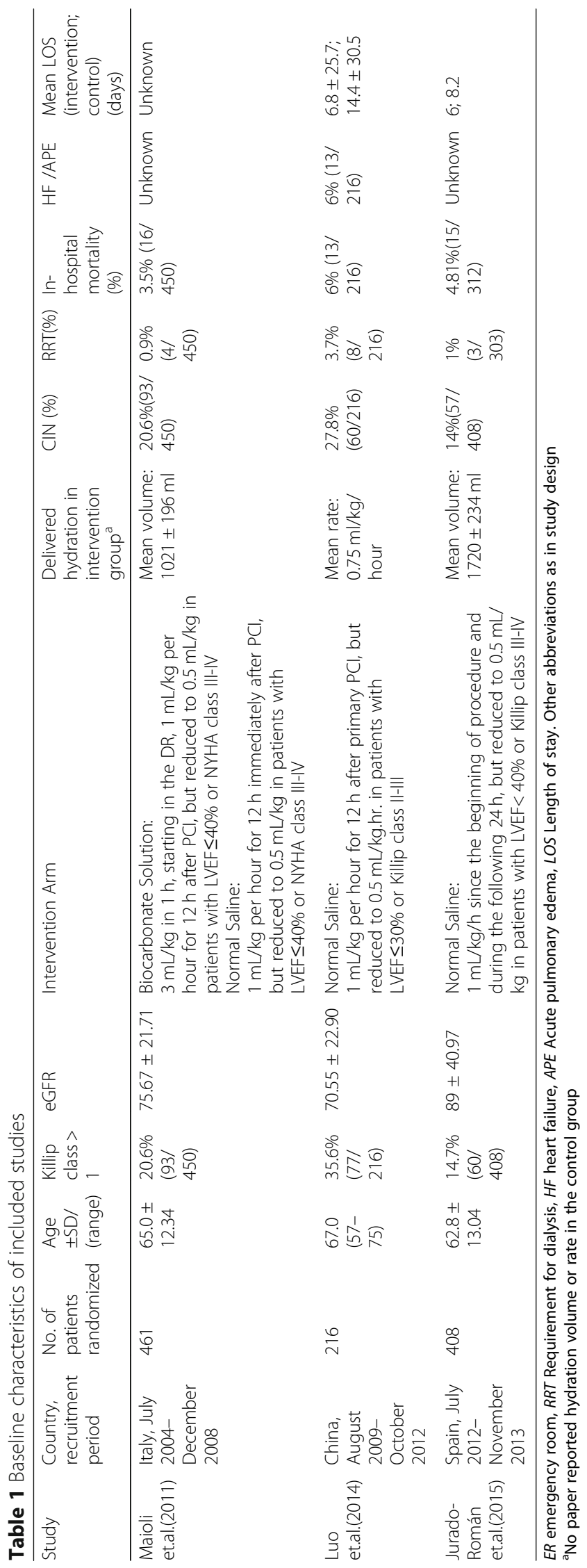




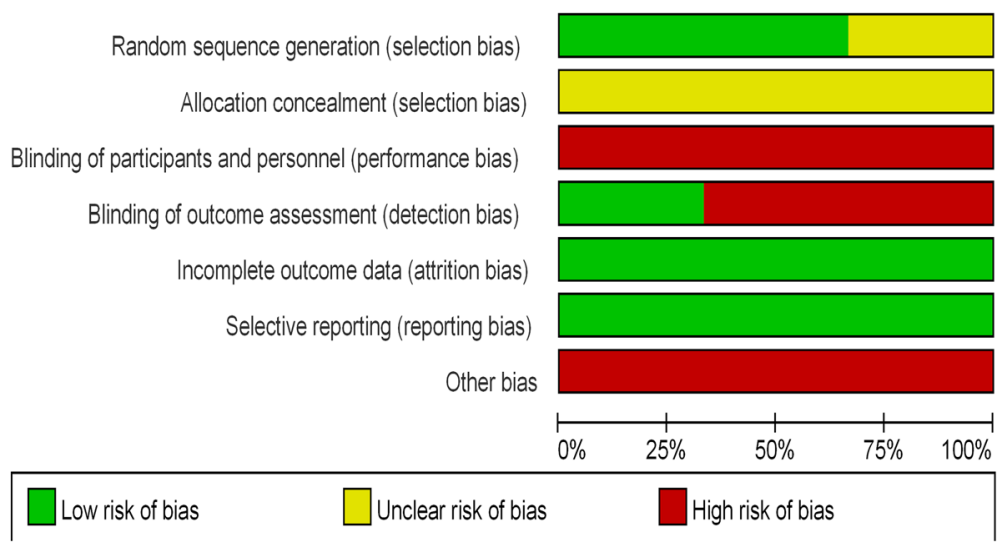

Fig. 2 Risk of bias graph: ach risk of bias item presented as percentages across all included studies

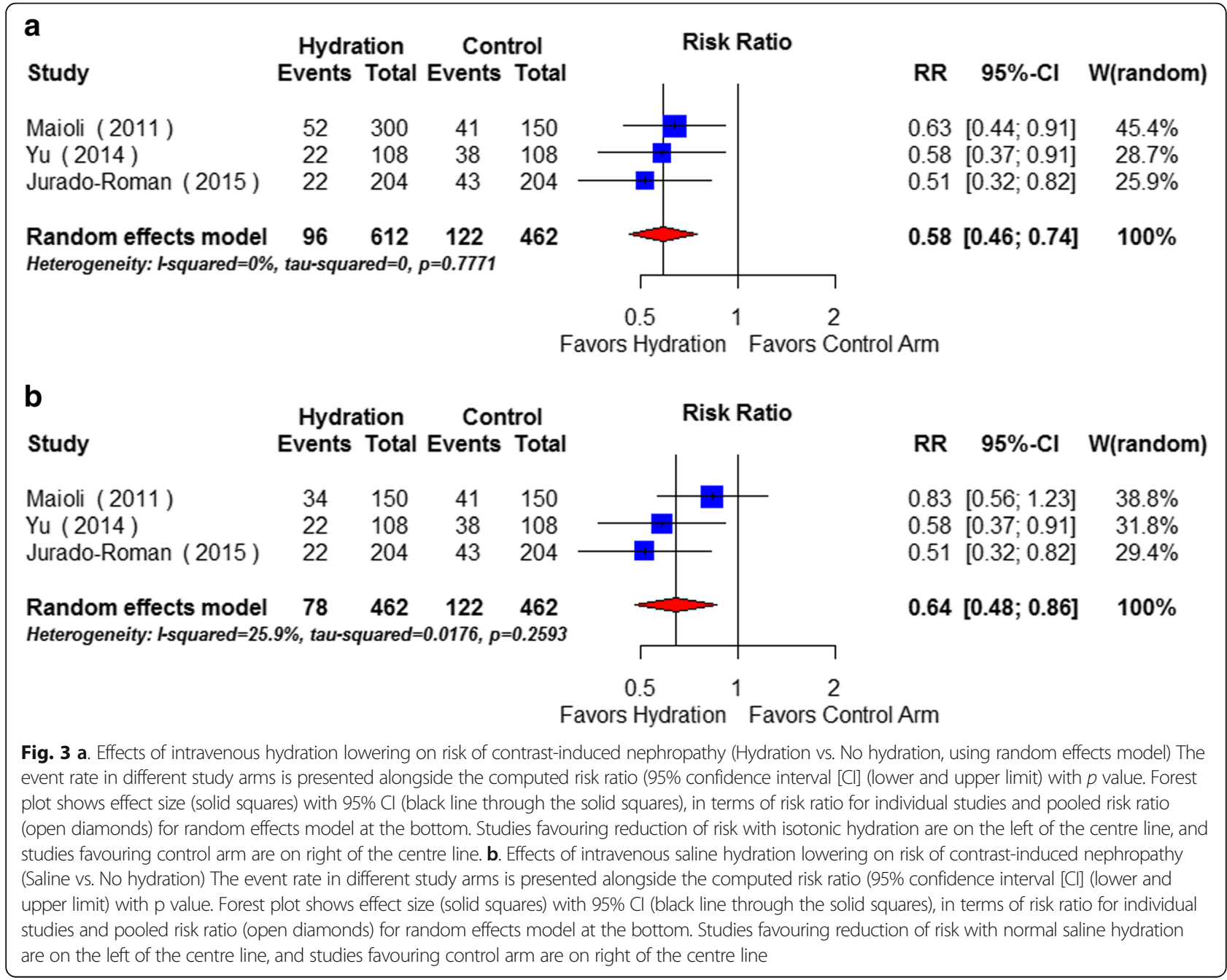


remained when the cohort that received bicarbonate solution was excluded (RR: 0.64 [95\%CI: 0.50 to 0.82$]$ ) (Fig. 3b).

\section{Secondary outcomes}

Overall 1.5\% (15/969) of participants required dialysis and $4.5 \%$ (44/978) died in-hospital. There was no statistically significant reduction in dialysis requirement (RR 0.52, 95\% CI 0.14-1.88) (Fig. 4) or all-cause In-hospital mortality (RR 0.56 ; 95\% CI: 0.30 to 1.02 ) in the intravenous hydration group (Fig. 5).

The outcomes of heart failure and acute pulmonary edema, were not consistently reported. Luo et al. report that acute pulmonary edema developed in 13 (6\%) patients ( 3 in the hydration group vs 10 in the no hydration group, $P=0.045)$, Jurado-Roman et al. report only that 42 patients $(20.6 \%)$ in the hydration arm had their fluid ceased due to "heart failure despite reducing the rhythm of the infusion" (Table 1). Maioli et al. did not report heart failure or acute pulmonary edema.

\section{Trial sequential analysis}

Assuming the modelled effect estimates, TSA estimated that an additional 790 study participants would need to be recruited beyond those studies to this point, to demonstrate a statistically significant improvement for In-hospital mortality. Similarly, an additional 8700 study participants would need to be studied to demonstrate an effect on the requirement for dialysis.

\section{Risk of bias across studies}

The funnel plot showed minimal asymmetry and Egger's regression intercept did not identify significant risk of bias (intercept $=-3.025$ [95\% CI: -18.545 to 12.495 ], df $=1, p=0.244$ ) (Additional file 6: Figure S4). However, this result should be interpreted with caution given that only 3 studies were included in the final analysis.

\section{Discussion}

This study is, to our knowledge, the first systematic review and meta-analysis assessing the effect of hydration on prevention of CIN in patients with STEMI undergoing primary PCI. We demonstrated a statistically significant reduction in the incidence of CIN associated with isotonic hydration. The effects upon the requirement for dialysis and all-cause In-hospital mortality were not statistically significant, despite large estimated effect sizes. The interpretation of these results is tempered by the small number of clinically significant events, as well as the moderate quality of the included studies.

Besides the preventative effect of intravenous hydration on the risk CIN, the baseline patients characteristics, including renal insufficiency, age, heart failure were contribute to the development of CIN and even mortality $[1,14]$. In addition, the association between CIN and mortality is strongly confounded by baseline clinical characteristics, large meta-analysis also showed CIN, as common complication of coronary angiography and/or coronary intervention (CAG/PCI), associated with increased lengthen of hospitalization, cardiovascular events, renal failure and mortality, so did that in Recent large STEMI Registry (e-PARIs) study among patients with STEMI undergoing primary PCI $[15,16]$. Therefor the risk stratification of CIN was the key step for prevention for patients with STEMI, while the infarct-related artery (IRA) only PCI were not associated with lower risk of CIN, adequate hydration maybe the optimal prophylaxis for primary PCI [17]. In the present three included studies, there were no significant dereference in characteristics of patients and coronary procedure, including treated coronary, age, diabetes, female, renal and heart function, which were predictors for CIN and in-hospital [4, 5, 9].

This review confirms that CIN is common (20.3\%) in patients with STEMI undergoing primary PCI and supports the use of hydration as prophylaxis in this setting. This is in contrast to a recent single centre study of high-risk patients receiving contrast during elective procedures where the incidence of CIN was only $2.7 \%$ [18].

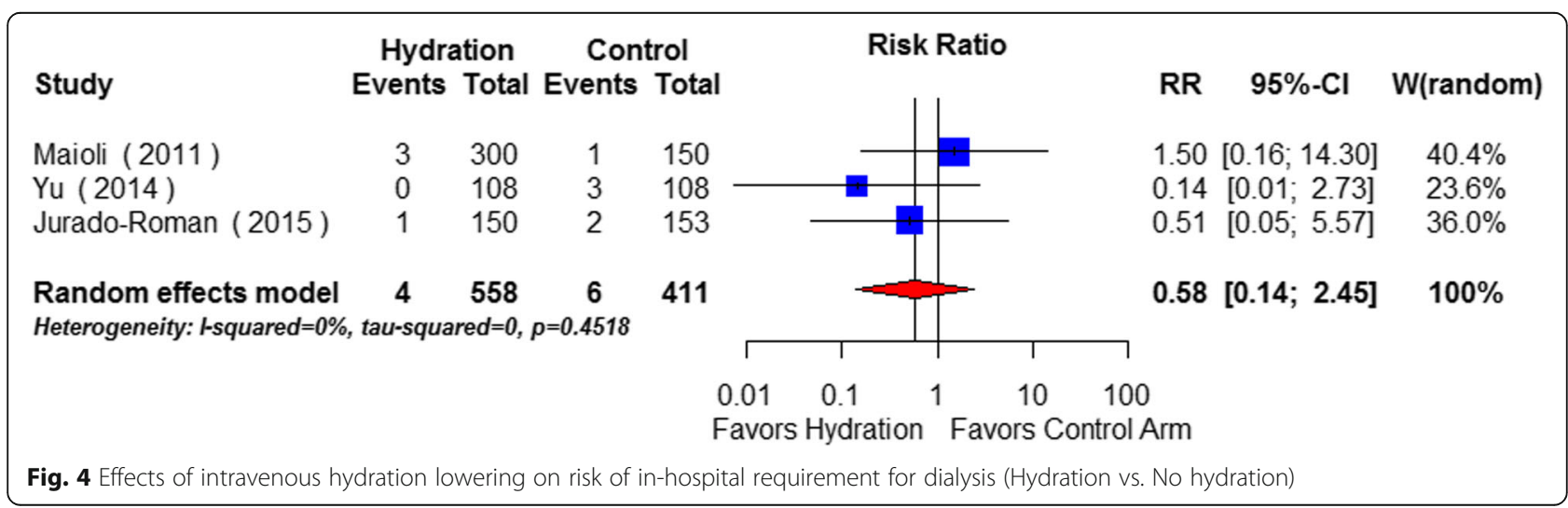




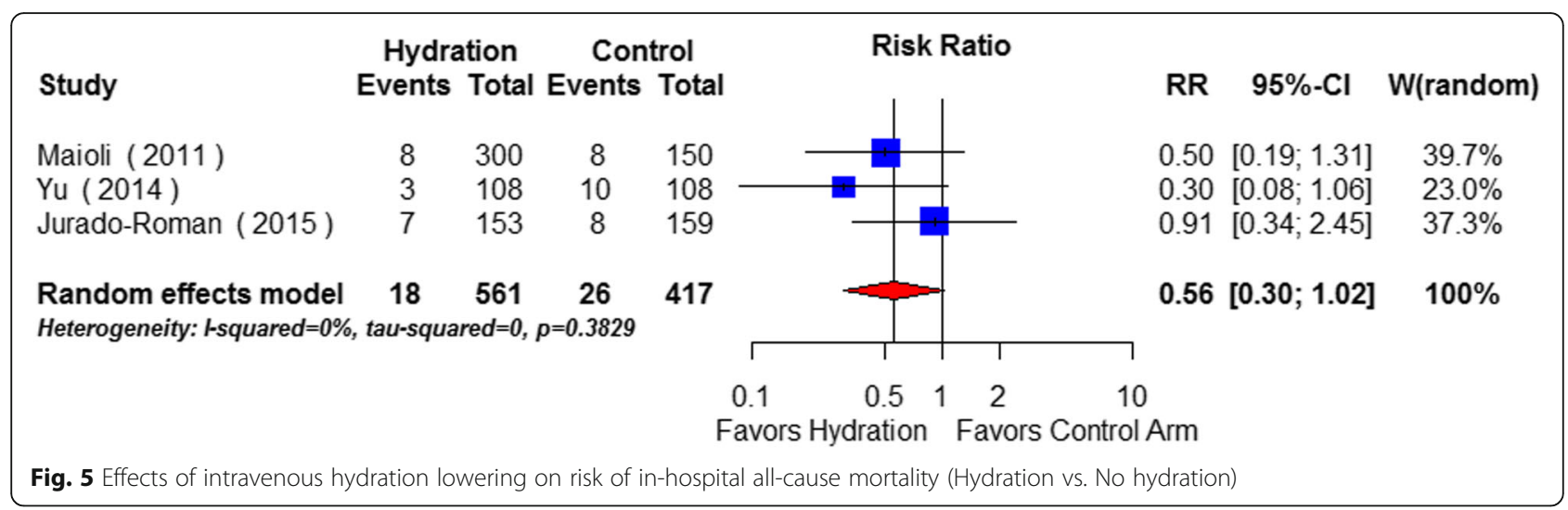

Renal guidelines recommend the use of isotonic hydration, rather than no volume expansion, but the clinical setting of acute STEMI poses some challenges for such therapy $[19,20]$. Avoidance of delays in reperfusion are paramount, and all three included studies commenced hydration with or after PCI, thus minimising delays in treatment. One study included a pre-hydration arm where there was no impact on door-to-reperfusion times [9].

A further priority is the avoidance of heart failure, which dramatically increases in-hospital mortality following STEMI [21]. Unfortunately the reporting of this outcome was not systematic, and the trials variably reported alterations to the fluid interventions in response to concerns about hydration state. Paradoxically, one study [Luo et al] reported significantly lower rates of acute pulmonary edema in the hydration arm $(2.8 \%$ vs 9.3\%). It is essential that the risk of heart failure is well understood before implementing routine hydration protocols for primary PCI.

Unfortunately, none of the included studies reported the delivered hydration volume in the control arm. It is likely that some hydration was administered as part of usual care, so it makes interpretation of the actual dose of fluid above and beyond usual care unclear. While the included studies did permit fluid for hypotensive patients, the possibility of systematic under-hydration in the control group cannot be excluded, which may have augmented the effect size seen in this analysis.

Potentially mitigating the concern around heart failure is the large, but not significant, effect sizes seen for the mortality and requirement for dialysis outcomes. While such effects are biologically plausible given the marked downstream impacts of acute kidney injury [22], the moderate study quality, the large sizes of the estimated effects, the small absolute number of events and the results of the TSA mean that more data is needed to define any effects. This might pose some challenges, as the treatment intervention is widely supported by guidelines and clinical practice, so cogent arguments would need to be made to ethically support withholding such treatment in a control arm of a study. Furthermore, the bearing of our findings upon future research and clinical practice rests heavily upon the weight given to the primary outcome of a $25 \%$ increase in serum creatinine. Others [23] have highlighted the questionable impact of small changes in serum creatinine upon clinically signficant outcomes, so we would argue that further studies in the setting of STEMI are needed.

The results of TSA indicate the challenges and opportunities facing future researchers. Although we demonstrated a consistent effect of hydration on CIN, given the methodological issues affecting the included studies the true effect size may be smaller than our results suggest. Similarly, the additional number of trial participants required to show an effect of hydration on important clinical endpoints, such as mortality and dialysis, may be significantly larger than the estimated 790 and 8700 from our analysis.

\section{Limitations}

All trials were limited by being single centre, unblinded and without clearly defined allocation concealment mechanisms. Furthermore there was inconsistent reporting of cross-over between allocated groups and the volume of fluid received by the control arm was not reported in any study. It is also not possible to define the most effective hydration protocol as all three studies used different starting times, rates and durations of hydration. Further information is expected from the ATTEMPT study (NCT02067195) evaluating the efficacy of aggressive hydration volume compared with general hydration $(\leq 500 \mathrm{~mL})$ for CIN following primary PCI [24]. Finally, the relative benefit of sodium bicarbonate solutions versus sodium chloride cannot be addressed by this review and we are unable to comment on the utility of adjunctive therapies such as $\mathrm{N}$-acetylcysteine or ascorbic acid.

\section{Conclusions}

In this analysis of three single centre trials of moderate quality, we demonstrated a significant reduction in CIN 
after STEMI with intravenous hydration. The effects of hydration upon the important clinical end points of the need for acute dialysis and mortality were not signficant, but suggested large possible effects. Despite the widespread recommendations to use saline hydration across medicine, our findings support the need for further studies in the STEMI setting, especially focussed upon clarifying the appropriate volume of treatment as well as heart failure and In-hospital mortality effects.

\section{Additional files}

Additional file 1: Search Strategy (DOCX $34 \mathrm{~kb})$

Additional file 2: Table S1. Additional characteristic of studies (DOCX $17 \mathrm{~kb}$ )

Additional file 3: Figure S1. Risk of bias summary: each risk of bias item for each included study (TIF $187 \mathrm{~kb}$ )

Additional file 4: Figure S2. GRADE assessment (TIF $42 \mathrm{~kb}$ )

Additional file 5: Figure S3. Effects of intravenous hydration lowering on risk of contrast-induced nephropathy (Hydration vs. No hydration, using fixed effects model) (TIF $12 \mathrm{~kb}$ )

Additional file 6: Figure S4. Funnel Plot for Subjective Assessment of Bias Among the Included Studies. Studies with larger sample size tend to accumulate at the top of the funnel and close to the centre line, with small studies toward the base. Funnel plot appears to have minimal asymmetry (TIFF $1456 \mathrm{~kb}$ )

\section{Abbreviations}

Cl: Confidence interval; CIN: Contrast-induced nephropathy; PCI: Percutaneous coronary intervention; RCT: Randomized controlled trial; ROS: Reactive oxygen species; RR: Risk ratio; SCr: Serum creatinine; STEMI: ST-segment elevationmyocardial infarction; TSA: Trial sequential analysis

\section{Acknowledgments}

We acknowledge Shaojun Xin and Xingcheng Liang in School of Pharmacy, Guangdong Pharmaceutical University, Guangdong, China for data extraction.

\section{Funding}

This work was supported by the The Progress in Science and Technology Project of Guangdong Province (grant no. 2015A030302037 by Yong Liu and 2014 B070706010 by Jiyan Chen); The National Science Foundation for Young Scientist of China (grant no. 81500520 to Yong Liu); and Youth Science and Technology Creative Research Groups of Sichuan Province (grant no. 2015 TD0013 by Daqing Hong).

\section{Availability of data and materials}

Data sharing is not applicable to this article as no datasets were generated or analyzed during the current study.

\section{Authors' contributions}

$M G, Y L, J C, D H$ and AYW: conception or design of the work, SC, YL, DH, RG and AYW: acquisition, analysis or interpretation of data. MG, YL, DH, AYW, BS, NT, MJ, $D B, A S, S I, J C, G S, J L$ and $G L$ : drafting the work or revising it critically for important intellectual content. YL, DH, AYW, RG, BS, GS, JL, GL, SC, NT, MJ, DB, AS, SI, JC and MG: final approval of the version published. All authors agreed to be accountable for all aspects of the work in ensuring that questions related to the accuracy or integrity of any part of the work are appropriately investigated and resolved. All authors read and approved the final manuscript.

\section{Ethics approval and consent to participate}

Not applicable (Meta-analysis).

\section{Consent for publication}

Not applicable.

\section{Competing interests}

The authors declare that they have no competing interests.

\section{Publisher's Note}

Springer Nature remains neutral with regard to jurisdictional claims in published maps and institutional affiliations.

\section{Author details}

'Department of Cardiology, Guangdong provincial Key Laboratory of Coronary Heart Disease Prevention, Guangdong Cardiovascular Institute, Guangdong General Hospital, Guangdong Academy of Medical Sciences, School of Medicine, South China University of Technology Guangzhou, Guangzhou, Guangdong, China. ${ }^{2}$ School of Medicine, South China University of Technology, Guangzhou, Guangdong, China. ${ }^{3}$ The George Institute for Global Health, the University of Sydney, Camperdown, Australia. ${ }^{4}$ Renal Department, Sichuan Academy of Medical Science \& Sichuan Provincial People's Hospital, Chengdu, China. ${ }^{5}$ Department of Neurosurgery, West China Hospital, Sichuan University, Chengdu, China. ${ }^{6}$ King Saud University, Riyadh, Saudi Arabia. ${ }^{7}$ Concord Clinical School, Sydney Medical School, University of Sydney, Camperdown, Australia.

Received: 15 October 2018 Accepted: 20 March 2019

Published online: 08 April 2019

\section{References}

1. Silver SA, Shah PM, Chertow GM, Harel S, Wald R, Harel Z. Risk prediction models for contrast induced nephropathy: systematic review. BMJ. 2015;351:h4395

2. Watabe H, Sato A, Hoshi T, Takeyasu N, Abe D, Akiyama D, Kakefuda Y, Nishina $\mathrm{H}$, Noguchi $Y$, Aonuma K. Association of contrast-induced acute kidney injury with long-term cardiovascular events in acute coronary syndrome patients with chronic kidney disease undergoing emergent percutaneous coronary intervention. Int J Cardiol. 2014;174:57-63.

3. Chong E, Poh KK, Liang S, Soon CY, Tan HC. Comparison of risks and clinical predictors of contrast-induced nephropathy in patients undergoing emergency versus nonemergency percutaneous coronary interventions. J Interv Cardiol. 2010;23:451-9.

4. Luo Y, Wang X, Ye Z, Lai Y, Yao Y, Li J, Liu X. Remedial hydration reduces the incidence of contrast-induced nephropathy and short-term adverse events in patients with ST-segment elevation myocardial infarction: a singlecenter, randomized trial. Intern Med. 2014:53:2265-72.

5. Jurado-Román A, Hernández-Hernández F, García-Tejada J, Granda-Nistal C, Molina J, Velázquez M, Albarrán A, Tascón J. Role of hydration in contrastinduced nephropathy in patients who underwent primary percutaneous coronary intervention. Am J Cardiol. 2015;115:1174-8.

6. Chong E, Poh KK, Liang S, Tan HC. Risk factors and clinical outcomes for contrast-induced nephropathy after percutaneous coronary intervention in patients with normal serum creatinine. Ann Acad Med Singap. 2010;39:374-80.

7. Levine GN, Bates ER, Blankenship JC, Bailey SR, Bittl JA, Cercek B, Chambers CE, Ellis SG, Guyton RA, Hollenberg SM, Khot UN, Lange RA, Mauri L, Mehran R, Moussa ID, Mukherjee D, Nallamothu BK, Ting HH; American College of Cardiology Foundation; American Heart Association Task Force on Practice Guidelines; Society for Cardiovascular Angiography and Interventions. 2011 ACCF/AHA/SCAI Guideline for Percutaneous Coronary Intervention. A report of the American College of Cardiology Foundation/American Heart Association task force on practice guidelines and the society for cardiovascular angiography and interventions. J Am CollCardiol 2011;58: e44-122.

8. American College of Emergency Physicians; Society for Cardiovascular Angiography and Interventions, O'Gara PT, Kushner FG, Ascheim DD, Casey DE Jr, Chung MK, de Lemos JA, Ettinger SM, Fang JC, Fesmire FM, Franklin BA, Granger CB, Krumholz HM, Linderbaum JA, Morrow DA, Newby LK, Ornato JP, Ou N, Radford MJ, Tamis-Holland JE, Tommaso CL, Tracy CM, Woo YJ, Zhao DX, Anderson JL, Jacobs AK, Halperin JL, Albert NM, Brindis RG, Creager MA, De Mets D, Guyton RA, Hochman JS, Kovacs RJ, Kushner FG, Ohman EM, Stevenson WG, Yancy CW. ACCF/AHA guideline for the management of ST elevation myocardial infarction: a report of theAmerican College of Cardiology Foundation/American Heart Association task Forceon practice guidelines. J Am Coll Cardiol. 2013;61(2013):e78-140. 
9. Maioli M, Toso A, Leoncini M, Micheletti C, Bellandi F. Effects of hydration in contrast-induced acute kidney injury after primary angioplasty: a randomized, controlled trial. Circ Cardiovasc Interv. 2011;4:456-62.

10. Higgins JPT, Green S. Cochrane handbook for systematic reviews of interventions. Available at: http://handbook.cochrane.org/. Accessed 16 Sept 2013.

11. V Thorlund K, Wetterslev J, Brok J, et al: User manual for trials equential analysis (TSA). Copenhagen, Denmark: Copenhagen Trial Unit, Centre for Clinical Intervention Research; 2011:1-115.

12. Higgins JP, Thompson SG, Deeks JJ, Altman DG. Measuring inconsistency in meta-analyses. BMJ. 2003 Sep 6;327(7414):557-60.

13. Borenstein M, Hedges LV, Higgins JPT, et al. Publication bias Introduction to meta-analysis. West Sussex, United Kingdom: John Wiley \& Sons, Ltd., 2009;277-292.

14. Sabroe JE, Thayssen P, Antonsen L, Hougaard M, Hansen KN, Jensen LO. Impact of renal insufficiency on mortality in patients with ST-segment elevation myocardial infarction treated with primary percutaneous coronary intervention. BMC Cardiovasc Disord. 2014;14:15. https://doi.org/10.1186/ 1471-2261-14-15

15. James MT, Samuel SM, Manning MA, Tonelli M, Ghali WA, Faris P, Knudtson ML, Pannu N, Hemmelgarn BR. Contrast-induced acute kidney injury and risk of adverse clinical outcomes after coronary angiography: a systematic review and meta-analysis. Circ Cardiovasc Interv. 2013;6(1):37-43.

16. Silvain J, Nguyen LS, Spagnoli V, Kerneis M, Guedeney P, Vignolles N, Cosker K, Barthelemy O, Le Feuvre C, Helft G, Collet JP, Montalescot G. Contrastinduced acute kidney injury and mortality in ST elevation myocardial infarction treated with primary percutaneous coronary intervention. Heart. 2018;104(9):767-72.

17. Chatterjee S, Kundu A, Mukherjee D, Sardar P, Mehran R, Bashir R, Giri J, Abbott JD. Risk of contrast-induced acute kidney injury in ST-elevation myocardial infarction patients undergoing multi-vessel intervention-metaanalysis of randomized trials and risk prediction modeling study using observational data. Catheter Cardiovasc Interv. 2017;90:205-12.

18. Nijssen EC, Rennenberg RJ, Nelemans PJ, Essers BA, Janssen MM, Vermeeren MA, Ommen W, Wildberger JE. Prophylactic hydration to protect renal function from intravascular iodinated contrast material in patients at high risk of contrast induced nephropathy (AMACING): a prospective, randomised, phase 3, controlled, open-label, non-inferiority trial. Lancet. 2017. Apr1;389(10076):1312-1322

19. KDIGO Clinical Practice Guideline for Acute Kidney Injury Kidney International Supplements. 2(2012), Pages 124-138.

20. Keeley EC, Boura JA, Grines CL. Primary angioplasty versus intravenous thrombolytic therapy for acute myocardial infarction: a quantitative review of 23 randomised trials. Lancet. 2003;361:13-20.

21. uffret V, Leurent $G$, Gilard M, Hacot JP, Filippi E, Delaunay R, Rialan A, Rouault G, Druelles P, Castellant P, Coudert I, Boulanger B, Treuil J, Bot E, Bedossa M, Boulmier D, Le Guellec M, Donal E, Le Breton H. Incidence, timing, predictors and impact of acute heart failure complicating STsegment elevation myocardial infarction in patients treated by primary percutaneous coronary intervention. Int J Cardiol. 2016;221:433-42.

22. Rewa O, Bagshaw SM. Acute kidney injury - epidemiology, outcomes and economics. Nat Rev Nephrol. 2014;10:193-207.

23. Zeng X, McMahon GM, Brunelli SM, Bates DW, Waikar SS. Incidence, outcomes, and comparisons across definitions of AKI in hospitalized individuals. Clin J Am Soc Nephrol. 2014;9(1):12-20.

24. Liu Y, Chen JY, Huo Y, Ge JB, Xian Y, Duan CY, Chen SQ, Jiang W, Chen PY, Tan N, RESCIND group. Aggressive hydraTion in patients with ST-elevation myocardial infarction undergoing primary percutaneous coronary intervention to prevenT contrast-induced nephropathy (ATTEMPT): study design and protocol for the randomized, controlled trial, the ATTEMPT, RESCIND 1 (first study for REduction of contraSt-induCed nephropathy followINg carDiac catheterization) trial. Am Heart J. 2016:172:88-95.

Ready to submit your research? Choose BMC and benefit from:

- fast, convenient online submission

- thorough peer review by experienced researchers in your field

- rapid publication on acceptance

- support for research data, including large and complex data types

- gold Open Access which fosters wider collaboration and increased citations

- maximum visibility for your research: over $100 \mathrm{M}$ website views per year

At BMC, research is always in progress.

Learn more biomedcentral.com/submissions 